\title{
Experts in Dialogue: An Introduction
}

\author{
Gábor Kutrovátz • Gábor Á. Zemplén
}

Published online: 26 July 2011

(C) Springer Science+Business Media B.V. 2011

\begin{abstract}
Different approaches to expertise and argumentation are discussed. After introducing the problem of expertise and its present day significance in a historical context, various connections with the study of arguments are highlighted. The need for and potential of argumentation analysis to contribute to existing research in social epistemology, science studies, and cognitive science, is discussed, touching on the problems of reasoning and argumentation, embodiment, tacit knowledge, expert context versus public context, expert disagreement, persuasion versus justification, and argument analysis as meta-expertise. As the arguments used by experts constitute a boundary object, we presume that a dialogue format is suitable to address central problems of the special issue "Rethinking Arguments from Experts".
\end{abstract}

Keywords Expertise - Argumentation - Social epistemology · Meta-expertise · Ad verecundiam arguments $\cdot$ Ethos

Sagredo: A long expected party of able and esteemed scholars gathered for the call. As we now have in our hands the collection of essays for a special issue on "Rethinking Arguments from Experts", we can start appreciating them and commence our discussion on the topic. The topic's relevance is increasing, hence the discussion is desirable and timely indeed...

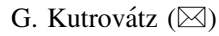

Department of History and Philosophy of Science, Eötvös Loránd University, Budapest, Hungary e-mail:kutrov@caesar.elte.hu

G. Á. Zemplén

Department of Philosophy and History of Science, Budapest University of Technology and Economics, Budapest, Hungary

e-mail: zemplen@filozofia.bme.hu 
Simplicio: Timely? Already at the outset of Western philosophical tradition, in Plato's dialogues we see Socrates who, despite his persistent attempts, is unable to find a satisfactory solution to the problem of experts. Do you recall his conversation with Critias and Charmides?

Nor, when another person claims to know something, will our friend be able to find out whether he knows what he says he knows or does not know it. But he will only know this much, it seems, that the man has some science; yes, but of what, temperance will fail to inform him.

Apparently so.

So neither will he be able to distinguish the man who pretends to be a doctor, but is not, from the man who really is one, nor will he be able to make this distinction for any of the other experts.

(Plato 1997a: 657)

Salviati: And does your appeal to authority disprove timeliness? The problem of experts is not culturally and historically universal, since the late-Medieval adjective "expert" (i.e. experienced) was first used as a noun in French only around 1870, together with the term "expertise". Since early modernity...

Sagredo: Timeliness aside I am glad to open our investigation for several reasons. On the one hand, we are witnessing a steady increase and complexification in the division of intellectual labor, a growing institutionalization of epistemic roles and structures, especially concerning problems that require some degree of scientific and technological competence. People are becoming more and more dependent on experts...

Simplicio: More and more? Who is to tell? Socrates conversed with the finest experts of his time representing various fields of knowledge-e.g. religion (Euthyphro), poetry (Ion), military affairs (Laches), rhetoric (Gorgias), dialectics (Euthydemus), sophist philosophy (Protagoras, Hippias) - in order to grasp what it means to have knowledge in these fields and in general. Life in the city-state already required experts, was dependent on them. The Greeks also grappled with the problem of expertise, and Socrates failed to find a definite answer. Do you think we will?

Salviati: My Simplicio, we might, provided we follow the venerable dialectical tradition that allows each participant to finish his words. Participation in a debate does require some restraint on the part of the participants. And to finish my words, a decisive segment of the early-modern and modern Western philosophical tradition contrasted the uncertainty of traditions, dogmas and testimonies with the soundness of autonomous cognition (based on individual sense-experience and reasoning). Just recall Kant's first maxim of the common human understanding, "to think for oneself" (Kant 2000: 174), and one understands why. Only recently, with increasingly institutionalized social roles and structures, it is progressively acknowledged that the vast majority of what individuals know, or believe to know - and what they do on the grounds of what they know-is based on other people's knowledge. Often, and also 
ideally, these others are outstandingly educated, well-informed, experienced, and reliable in certain fields, i.e. they are experts.

Sagredo: Indeed. In various fields, emphasis on the problem of expertise intensified in recent decades. "A significant milestone is reached when a field of scientific research matures to a point warranting publication of its first handbook", claims the first handbook of expertise (Ericsson et al. 2006: 3), summarizing mainly the relevant psychological research in 900 dense pages. In the same year, a volume entitled "Philosophy of Expertise" was published (Selinger and Crease 2006), offering a selection from the most important papers dealing with expertise in social epistemology, a field discussing the social aspects of knowledge and the role of testimonial knowledge. In the social studies of science, Harry Collins and Robert Evans announced the programme called Studies of Expertise and Experience, in a paper that has become one of the most frequent points of reference in the field (Collins and Evans 2002; see also Collins and Evans 2007). Expertise turned out to be important in other fields, too, such as the theory of management, risk assessment, artificial intelligence research, didactics, etc.

Salviati: Of course, the wide variety of relevant disciplines breeds many different concepts of expertise and poses many different questions, and there is no coherent theoretical approach or conceptual framework embraced by even one discipline, not to mention all of them together. A body of relevant psychological literature addresses the question of what special competences experts possess, how these develop, how their performance is influenced by different factors, and what empirical methods enable us to measure the performances. In artificial intelligence research, the focus is on expert systems and problem solving, often understood in terms of algorithmic procedures. Some philosophers examine how to reconcile the notion of knowledge with the social dimensions of the knower, others study how expertise relates to social theories and what types of ethical and political problems arise. A number of sociologists and social psychologists aim to describe how the status of expertise is attributed and how mechanisms of trust function.

Simplicio: And what do we gain by listening to all these scientists and philosophers, or you lecturing on them? Is not common sense sufficient? Plato reports that when someone testifies at the Assembly who is not an expert, people "laugh at him and shout him down until he either gives up trying to speak and steps down himself, or the archer-police remove him forcibly by order of the board" (Plato 1997b: 755). Like us, the citizens of Plato's Athens recognized that they needed to rely on expert knowledge in all walks of life, and they had an intuitive understanding of who the experts were.

Salviati: And like ancient philosophers, we do not have a satisfactory theoretical grasp on this intuitive understanding of a social phenomenon of vital significance in democracies: we cannot explain sufficiently what it means for someone to be an expert and how to identify reliable expert sources. Plato's groundbreaking inquiries show that the central question of epistemology, "What does it mean to know", is essentially linked with questions like "What does it mean to know better than others" and "What does it mean to know something on the basis of what others know better". 
Sagredo: And this dependence on others is not only epistemic, since a huge and ever growing range of our practices is also grounded on expert performance. Plumbers, car repairmen, or chess masters are also experts, and they know how to do certain things far better than most people, but their excellence is constituted by their performance, rather than by abstract propositional knowledge. Philosophy alone is not enough, neither is psychology or sociology or any other single discipline. "Expertise" has become a boundary object (Star and Griesemer 1989), a common subject of many different approaches and fields. All this implies that, in our present culture, we need a multi-disciplinary approach bringing together many issues, concepts, and methodologies borrowed from various disciplines dealing with different but overlapping topics such as science, discursive practices, argumentation, the social structuring of knowledge, cultural interests and values, etc.

Simplicio: You mention argumentation. Yet when you discussed the recent upsurge in literature, you did not speak of this field of study.

Salviati: You are right. Disciplines extensively studying expertise and expert disagreement were mostly ignorant about the parallel research in argumentation (e.g. Walton 1997, 2008). It is only the latest of the handbooks of science and technology studies that has a chapter on argumentation (Keith and Rehg 2008). Such late reception is understandable, as both research fields have their own methodologies, journals, and conferences. But it is also true that emerging disciplines can be itchy about their boundaries, and decades of work in rhetoric of science have had limited impact on neighbouring fields. Expertise is a boundary object, and with many disciplines with claims on the territory we can also expect some boundary work (Gieryn 1983).

Sagredo: Yet there are obvious reasons that connect the problem of expertise to the study of arguments. The first that comes to my mind is this: When an expert needs to make up her mind concerning a problem of her field, her reasons may be expressed as arguments, so the best expert opinions should be supported by good and prudent arguments.

Saliviati: Dear Sagredo, you seem to be transgressing the boundary between the realm of normative and the realm of descriptive. If you claim that good arguments "should" support expert claims, you need to appeal to a normative concept of what it means for an argument to be good-surely there are such theories, but let rationalists tread these paths. But if you say that it is arguments that make experts decide, I humbly but firmly object to that.

Simplicio: Come on, Salviati, how would you come up with a reliable solution to any problem without deference to arguments? What guides you if not explicable reasons? What supports you if not logic?

Salviati: Just recall my example of chess masters. Surely a great variety of complex cognitive mechanisms and schemes operate when they perform their expertise, but the bulk of these cannot be treated as reasoning in any traditional sense. Although the role of embodiment is still hotly debated (Selinger et al. 2007), it certainly appears difficult to reconstruct these decisions as grounded in argumentative processes. The same goes for expert level repairmen, expert level vehicle drivers, expert level language users, etc.: the import of theoretical "knowthat" is insignificant compared to the weight of practical "know-how". 
Sagredo: You chose your examples cleverly, Salviati. But we could still agree that there are forms of expertise where reasoning and the use of arguments play a vital role. Argumentative discourse in the public domain is accountable, and " "propositionality" should be considered one of the most significant and valuable achievements of deliberative discourse" (Goodwin, this volume). Just think of science, an epistemically privileged enterprise of our times. In order for a claim to be accepted by a community, arguments must be explicated for it. Also, contemporary science typically deals with "complex issues that exceed the expertise of any single person" (Rehg, this volume), and discursive cooperation is essential. Scientific "facts" emerge from the argumentative discourses among scientists - another field of interest for us. Or would you deny that one of the major insights of your favoured discipline, the social studies of science, is that knowledge production in science is a collective process? In fact, more and more social epistemologists and even cognitive scientists work in frameworks that do not treat the social as reducible to the individual.

Salviati: I am glad to accept that much. Experts within science have to rely on, and trust, other experts' claims, otherwise there would be no progress in science. How else could they stand on the shoulders of giants? Experts in large research groups are "epistemically dependent" on one another if their aim is to produce knowledge. On the other hand, what I would deny is that knowledge always travels between scientists in the medium of veridical or argumentative discourse. Another robust insight of science studies is the recognition of the role of tacit knowledge. "To become an expert in a technical domain means acquiring the tacit knowledge pertaining to the relevant domain of expertise" (Collins and Weinel, this volume). And philosophical and linguistic considerations also support the view...

Simplicio: I am familiar with your Wittgensteinian commitments, so please spare me for now of your "forms of life" and fancy phrases like "enculturation" and "socialization". They surely play their part in knowledge production, and perhaps a good part, too. But Sagredo's claim was that there are arguments in science, and these arguments give strong reasons for accepting or refuting standpoints. Where else if not in science? I suppose that even people in the social studies of science do the same, or at least try. I tend to consent that scientific discourse brings expertise and arguments together.

Sagredo: And this is not a trivial insight, because in today's scientific papers much of the explicit argumentation is masqued by the institutionalized literary form of scientific articles (Suppe 1998) favoring a factual discourse, itself a result of a long process of development, with recurring debates and controversies. So I suggest we move on to the communication between scientific experts and the lay public. Even if tacit knowledge is essential for practicing science and the internal communication of scientific core groups, laypeople have at most limited access to the tacit knowledge base that scientists rely on, so the necessity to explicate arguments for standpoints becomes even more vital here. By making a "distinction between an expert context and a public context" (Zenker, this volume), another perspective opens for the study of argumentation to examine questions related to the problem of expertise. 
Simplicio: Hold on for a minute. Why should experts argue when informing laypeople? They are the experts after all, and laypeople should accept whatever experts say. This is why we have experts: to place our epistemic trust in them. And research in cognition also supports the view that even when arguments are extant, they are not always analysed; "why bother evaluating arguments if one is convinced by the expertise in the first place?" (Mercier, this volume). Moreover, most expert arguments, like scientific arguments, seem much too technical for laymen to understand, let alone assess, so why would experts want to hear the public's opinion? To assess an expert you need to be an expert yourself.

Salviati: True, and I have never had the ambition to challenge good-old scientific claims like Maxwell's equations, even though I admit I never understood them properly. But I am no physicist, why should I care about them if I never need to rely on knowing them? But I do care about the types of food I should eat, how to remain healthy, or whether the use of cell phones increases my risk of developing cancer, and even to what degree my lifestyle contributes to climate change. And, my dear Simplicio, these are the questions that make me need scientific expert advice and, at the same time, these are the questions where there is limited consensus. Hence for me, a layman, the basic question is: "when experts disagree, whom should we trust" (Rehg, this volume)?

Simplicio: All right, I must admit that controversies around publicly relevant issues like Intelligent Design or the reports of the International Panel of Climate Change (IPCC) fascinate me. I am intrigued to understand the reasons for and the impact of the lack of consensus, since "much effort, both implicit and explicit, goes into the selection of experts, in terms of background assumptions as well as institutional organisation" (Gelfert, this volume). Just like in the quoted case from Plato, experts or purported experts are forced to defend their position in legal or policy settings. With this context in mind, aren't experts better off to persuade the public with all the available tools, rather than waste time trying to convince them with complex technical arguments? After all, "we cannot easily separate the acquisition of knowledge acquired through the claims of experts from emotional reactions to those experts" (Tindale, this volume). In such cases, rhetoric rules over logic, and ethos is far more decisive than good reasons. Public settings easily produce what a philosopher of law called "a lucrative "market" for demeanor itself" (Brewer 2006: 39).

Salviati: But if you contrast "good" arguments with "mere" persuasion, you do injustice to the venerable tradition of rhetoric that deals with important aspects of public argumentation, just as you dismiss the insight that grants rhetoric its own reasonableness. Public utterances can have both persuasive and justificatory functions. Furthermore, you seem to forget that in these controversial cases experts often engage in public debates in order to convince the audience, and not their opponents. Dialectical attitudes and performances can be good indicators of competence, or the lack thereof, even when the details of the arguments are too esoteric for the ears of the public (Goldman 2006: 22-24).

Sagredo: And as we are turning our attention from the expert perspective to the lay perspective, we can reformulate Salviati's "basic question": "how, in the course of complex and confused civic deliberations, nonexpert citizens can possibly figure 
out which statements from purported experts deserve their trust"? (Goodwin, this volume) It seems to follow that "the critical assessment of expert opinions ... may greatly benefit from the insights concerning the reconstruction and evaluation of argumentative discourse developed within the field of argumentation theory" (Wagemans, this volume). After all, arguments should be approached with some healthy suspicion when we see them as self-contradictory or incoherent, or when participants in a discussion carelessly employ argument schemes such as argumentum ad verecundiam or argumentum ad hominem, not to mention excessive appeals to emotions.

Simplicio: Wait a minute, if I need these technical terms to benefit from evaluating the arguments given by experts, does this mean that I have to become an expert in argumentation? Most people don't know what ad verecundiams are and how to judge them: it needs some training and experience to deal with them, in other words, it requires a level of expertise. Do you want to collapse the distinction between experts and laypeople? What becomes of expertise if everybody has to be an expert?

Salviati: I am more than ready to do away with this distinction. First, if experts are seen as epistemically distinguished members of the society at the expense of others, then principles of democratic citizenship become endangered. "Expertise is a kind of authority, and so it stands in contrast to liberal democratic values." (Majdik and Keith, this volume)

Simplicio: I am happy to see that at last you start to reveal some normative intentions, but do not throw out the baby with the bath water. We need the authority of experts, as our discussion has shown so far. It seems that "the question is not whether expertise should have authority, but what the bounds of that authority should be, and how inclusive they are." (Majdik and Keith, this volume)

Salviati: And I agree with that. But the point is that we are all experts, only on different issues-hence the need for mutual epistemic dependence. Experts meet the public in a complex space of deliberation and negotiation where every agent is a stakeholder of her own interests. Also, even regarding a single problem field, there is no clear line: some are more experts than others, according to the degree of acquisition of skills and competences (Dreyfus and Dreyfus 2005). After all, why deny that "expert reasoning follows the same pattern as layman's reasoning" (Mercier, this volume). Some even prefer to use "novice" as opposed to "layman". Ludwik Fleck noted three generations ago that popular science "furnishes the major portion of every person's knowledge. Even the most specialized expert [exakteste Fachmann] owes it to many concepts, many comparisons, and even his general viewpoint. It thus constitutes the general operative factor in cognition and must accordingly rank as an epistemological problem." (Fleck 1981, 112)

Sagredo: While experts are non-experts in many fields, non-experts can be experts at the same time, at least with respect to arguments. On the one hand, they are laypeople regarding the problems about which they seek expert advice. On the other - to ease your epistemological problem - they can be experts regarding the ways to assess and evaluate the reliability of expert claims. The latter requires competences different from those of the experts. 
Simplicio: Yes. In the case of Intelligent Design, or the controversy surrounding the IPCC reports, I do not need to understand all of the arguments. For me it is sufficient to understand only the social situation of purported experts. If they are not real scientists but use the language of science, they are simply pseudo-experts. One possibility is to "use social expertise as a resource for judging expert claims" (Collins and Weinel, this volume). This setting invokes the distinction between subject-level and meta-level: when we have to judge expert claims without being experts ourselves, we can still be meta-experts and judge the experts themselves.

Salviati: I see your point. In science and technology studies this has long been recognized. Already the philosopher of science Imre Lakatos claimed that that "most scientists tend to understand little more about science than fish about hydrodynamics" (Lakatos 1970: 148n), and...

Simplicio: ...Before taking comparisons too seriously, recall the well-known (though perhaps apocryphal) opinion of the physicist Richard Feynman, who famously said that "philosophy of science is about as useful to scientists as ornithology is to birds..."

Salviati: ...And that is an issue that I find irrelevant here. What I want to say is that it is practicing scientists who know science best, but it does not mean that they are the ones who know the most about science. In fact, meta-scientific claims made by scientists reveal many different positions, while scientific claims made by the same scientists are far more convergent (Shapin 2001). Listen to your beloved Socrates: "But if it seems right, Critias, let us now grant this point, that the existence of a science of science is possible" (Plato 1997a: 656). Fortunately, we have a range of partly overlapping disciplines as candidates for meta-scientific enterprises: history of science, philosophy of science, sociology of science, science and technology studies...

Simplicio: These are quite well-established disciplines. What about argumentation studies? Can we call that a field of expertise?

Sagredo: Well, this you must judge for yourself. Reading the collection of articles I have no doubt that you will see: argumentation is a field of expertise, and one that has a great deal to say about expertise. When it comes to expertise, Goodwin points to convergences between argumentation theory and science studies, Gelfert discusses the possibility of rapprochement between social epistemology and argumentation theory, and Mercier develops a novel perspective on argumentation and expertise based on cognitive science. Pragma-dialectical perspectives appear in Wagemans, while Tindale utilizes the rhetorical tradition. Zenker makes sense of bias for argumentation theorists, Majdik and Keith analyze a case study on myopic vision, and Rehg discusses the result of the collective myopia of our times, climate change. Collins and Weinel connect their "studies of expertise and experience" to argumentation studies, and develop their characterization of transmuted expertise.

Simplicio: What a medley of approaches and perspectives-I wonder what this cabinet of curiosities reveals.

Salviati: And I am curious to see how they complement one another. My dear friends, may I suggest not to wait a moment longer, but start reading the texts now.

Sagredo: And so at last we have reached consensus on something, with no difference of opinion to be resolved. 


\section{References}

Collins, H., and R. Evans. 2002. The third wave of science studies: Studies of expertise and experience. Social Studies of Science 32(2): 235-296.

Collins, H., and R. Evans. 2007. Rethinking expertise. Chicago: The University of Chicago Press.

Dreyfus, H., and S.E. Dreyfus. 2005. Peripheral vision: Expertise in real world contexts. In: Organization studies, 779-792.

Ericsson, K.A., N. Charness, P.J. Feltovich, and R.R. Hoffman, eds. 2006. The Cambridge handbook of expertise and expert performance. Cambridge: Cambridge University Press.

Fleck, L. 1981. Genesis and development of a scientific fact. Chicago: University of Chicago Press.

Gieryn, T.F. 1983. Boundary-work and the demarcation of science from non-science: Strains and interests in professional ideologies of scientists. American Sociological Review 48: 781-795.

Kant, I. 2000. Critique of the power of judgment (trans: Guyer, P., and Matthews, E.). Cambridge: Cambridge University Press.

Keith, W., and W. Rehg. 2008. Argumentation in science: The cross-fertilization of argumentation theory and science studies. In The Handbook of Science and Technology Studies, ed. Hackett, E.J., Amsterdamska, O., Lynch, M., J. Wajcman, 241-258. Cambridge, MA: The MIT Press, Published in cooperation with the Society for Social Studies of Science.

Plato. 1997a. Charmides. In Plato: Complete works (trans: Sprague, R.K), ed. Cooper, J.M, 639-663. Indianapolis/Cambridge: Hacket Pubishing Company.

Plato. 1997b. Protagoras. In Plato: Complete works (trans: Lombardo, S., and Bell, K.), ed. Cooper, J.M, 746-790. Indianapolis/Cambridge: Hacket Pubishing Company.

Selinger, E., and R.P. Crease, eds. 2006. The philosophy of expertise. New York: Columbia University Press.

Selinger, E., H. Dreyfus, and H. Collins. 2007. Interactional expertise and embodiment. Studies in the History and Philosophy of Science 38(4): 722-740.

Shapin, S. 2001. How to be antiscientific. In The one culture? A conversation about science, ed. Jay A. Labinger and Harry. Collins, 99-115. Chicago: Univesity of Chicago Press.

Star, S.L., and J.R. Griesemer. 1989. Institutional ecology, 'translations' and boundary objects: Amateurs and professionals in berkeley's museum of vertebrate zoology, 1907-1939. Social Studies of Science 19(4): 387-420.

Suppe, F. 1998. The structure of a scientific paper. Philosophy of Science 65(3): 381-405.

Walton, D. 1997. Appeal to expert opinion: Arguments from authority. University Park: Pennsylvania State University Press.

Walton, D. 2008. Witness testimony evidence: Argumentation, artificial intelligence, and law. Cambridge: Cambridge University Press. 